\title{
A Disposition-Behavior Congruity Model of Perceived Freedom
}

\author{
YAACOV TROPE \\ The Hebrew University of Jerusalem
}

AND

EUGENE BURNSTEIN

The University of Michigan

Received April 11, 1976

\begin{abstract}
Three expcriments were conducted to test a disposition-behavior congruity model of perceived freedom. The model was applied to attributions of freedom to actors who possess one of several dispositions and who can choose a behavior that is congruent or incongruent with this disposition. The model posits that attributions of freedom to an actor can be predicted from the conditional probabilities that the actor would choose each behavior available to him if he possessed the disposition congruent with it. This hypothesis was supported. However, contrary to expectations, the contribution to judgment of each conditional probability was not a function of the probability that the actor actually possessed the behaviorcongruent disposition.
\end{abstract}

Perceived freedom has been investigated within the framework of several social psychological theories such as cognitive dissonance theory (Brehm \& Cohen, 1962), the theory of psychological reactance (Brehm, 1966), and attribution theory (Kelley, 1967). In these theories, perceived freedom has been viewed as an important variable mediating psychological phenomena such as postdecision dissonance, reactance, and inference of personal traits from observed behavior. Past research, however, has typically focussed on the consequences of perceived freedom. Only recently have attempts been made to characterize and define the concept quantitatively. Most of these recent studies (Harvey \& Harris, 1975; Harvey \& Johnston, 1973; Jellison \& Harvey, 1973; Steiner, Rotermund, \&

This article is based on the first author's doctoral dissertation at the University of Michigan, the second author serving as chairman of the doctoral committee. Thanks are due to the members of the doctoral committee: Dorwin Cartwright, William Gamson, David Krantz, and Robert B. Zajonc, for their valuable help throughout this research. The research was supported by a grant from the National Institute of Mental Health (MH-16950-06) and a grant from the Israel Commission for Basic Research.

Requests for reprints should be sent to Yaacov Trope, Department of Psychology, The Hebrew University of Jerusalem, Jerusalem, Israel. 
Talaber, 1974) tested the idea that perceived freedom increases as the behavior alternatives become more nearly equal in attractiveness (Steiner, 1970) or probability (Ajzen, 1971).

Several attribution theorists identified a different aspect of perceived freedom, namely, the perception that the actor's behavior corresponds to and therefore satisfies his internal dispositions. Kelley (1967) specifically suggested the "possibility of defining volition in terms of perception of acting according to one's own intention" (p. 218). In support of this notion, Kruglanski and Cohen $(1973,1974)$ demonstrated that observers attribute more freedom to an actor whose behavior is congruent rather than incongruent with his presumed internal dispositions. It follows that before observing the actor's behavioral choice, the amount of freedom attributed to him should be related positively to the expectancy that his dispositions will be expressed in his behavior. This expectancy, in turn, depends on the value of extrinsic rewards for choosing each behavior, which is added to the inherent of intrinsic value of choosing it. Extrinsic rewards constitute either facilitative or inhibiting causes (Kelley, 1971) that lower the expectancy that the actor's behavior will be guided solely by a congruent disposition. That is, regardless of whether or not the actor has this disposition, he would be expected to choose a behavior that is associated with large extrinsic rewards. According to Nisbett and Valins (1971, p. 67), freedom is attributed to the extent that such extrinsic (as opposed to intrinsic) considerations are absent. Finally, the notion of congruence between personal dispositions and behavior is of central importance in Jones and Davis' (1965) analysis of correspondent attribution and in Kruglanski's (1975) theory of endogenous versus exogenous attribution. In fact, these authors suggest that an attribution is correspondent or endogenous when the actor's goal and behavior can be similarly described or conceptualized. Moreover, according to Kruglanski (1975), more freedom will be imputed when the attribution is endogenous than when it is exogenous.

Below we present a model that takes into account the determinants of perceived freedom discussed in the preceding paragraph.

\section{A Disposition-Behavior Congruity (DBC) Model of Perceived Freedom}

Suppose an observer thinks that an actor in a given choice situation has one of several dispositions, $D_{1}, \ldots, D_{n}$. (In this context, "disposition" is a generic term that may refer to either goals, tendencies, attitudes, or preferences). For simplicity, we will assume that the dispositions are mutually exclusive. (Similar considerations apply when they are not.) Suppose further that the actor is offered several mutually exclusive behavior alternatives, $B_{1}, \ldots, B_{m}$. We suggest that the observer 
assesses the attractiveness or value of each behavior to the actor, given that the actor has each of the alternative dispositions considered. This assessment is based upon two considerations. One is the intrinsic value of the behavior, which is simply defined as the extent to which performance of the behavior satisfies the particular disposition the actor may have. The other is the situational or total value of the behavior, which is determined by all sources of attractiveness operating in the situation, intrinsic as well as extrinsic.

These perceived behavioral values give rise to subjective conditional probabilities that actors who possess the different dispositions will choose the available behaviors. We distinguish between two sets of conditional probabilities. One is based on the intrinsic values of the behaviors, $P_{\text {int }}(B \mid D)$, and the other is based on their total values, $P(B \mid D)$. Considering, for example, $D_{i}$ and $B_{j}$ we have (a) the conditional probability that if the actor possesses $D_{i}$ he will choose $B_{j}$ only because of the intrinsic value it has for him as a person possessing $D_{i}$, and (b) the conditional probability that if the actor possesses $D_{i}$, he will choose $B_{j}$ on the basis of its total value. Thus, with $n$ dispositions and $m$ behaviors, we have $n \times m$ conditional probabilities based on intrinsic value and $n \times m$ conditional probabilities based on total value.

The amount of freedom attributed to an actor who is assumed to have a given disposition $D_{i}$ may be negatively related to the absolute discrepancies between $P\left(B_{j} \mid D_{i}\right)$ and $P_{\text {int }}\left(B_{j} \mid D_{i}\right)$, summed over the behavioral alternatives available, that is, $\sum_{j}\left|P\left(B_{j} \mid D_{i}\right)-P_{\text {int }}\left(B_{j} \mid D_{i}\right)\right|$. (Other measures such as the sum of squared differences are also plausible.) Since $\sum_{j} P\left(B_{j} \mid D_{i}\right)=\sum_{j} P_{\text {int }}\left(B_{j} \mid D_{i}\right)=1$, the sum of absolute differences ranges from 0 to 2 . By substracting this sum from 1, we obtain an index, ranging from -1 to +1 , of the amount of freedom an actor possessing $D_{i}$ is perceived to have in a situation before making his choice.

The above formulation theoretically predicts the amount of freedom an observer will attribute to the actor if he is certain that the actor has a particular disposition. In practice, however, an observer may often be uncertain of the actor's disposition. In such cases, it seems reasonable to suppose that the relative weight attached to the freedom implied by each disposition $i$ will be a function of the prior probability that the actor has this disposition, or $P\left(D_{i}\right)$. This suggests that when $n$ dispositions are possible, the perceived freedom of the actor $(P F)$ will be predictable from the quantity

$$
P F=\sum_{i=1}^{n} P\left(D_{i}\right)\left[1-\sum_{j=1}^{m}\left|P\left(B_{j} \mid D_{i}\right)-P_{\text {int }}\left(B_{j} \mid D_{i}\right)\right|\right] .
$$

Stated generally, Equation 1 suggests that freedom in a choice situation is 
attributed to the extent that the choice is expected to be guided by intrinsic rather than by extrinsic considerations.

Equation 1 can be simplified when applied to the situations considered empirically in this study, namely, situations where each behavioral alternative is congruent with one and only one internal disposition. For example, if the behavioral choice is between arguing for $\left(B_{1}\right)$ or against $\left(B_{2}\right)$ an attitudinal object, then a positive attitude $\left(D_{1}\right)$ or a negative attitude $\left(D_{2}\right)$ toward the object might be considered as dispositions, $B_{1}$ being congruent only with $D_{1}$ and $B_{2}$ being congruent only with $D_{2}$. For such situations it can be assumed that the conditional probabilities based on intrinsic value are close to unity for congruent pairs of behaviors and dispositions, i.e., $P_{\text {int }}\left(B_{i} \mid D_{i}\right)=1.0$, and are close to zero for incongruent pairs of behaviors and traits, i.e., $P_{\text {int }}\left(B_{j} \mid D_{i}\right)=0.0$ for $j \neq i$. If we substitute these values into Equation 1, the latter can be written only in terms of prior probabilities and conditional probabilities that are based on total value: ${ }^{p}$

$$
P F=\sum_{i} P\left(D_{i}\right)\left[P\left(B_{i} \mid D_{i}\right)-\sum_{j \neq i} P\left(B_{j} \mid D_{i}\right)\right] .
$$

Since

$$
\sum_{j} P\left(B_{j} \mid D_{i}\right)=P\left(B_{i} \mid D_{i}\right)+\sum_{j \neq i} P\left(B_{j} \mid D_{i}\right)=1,
$$

it follows that

$$
\left.\sum_{j \neq i} P\left(B_{j} \mid D_{i}\right)=1-P\left(B_{j} \mid D_{i}\right)\right]
$$

and therefore we can write

$$
P F=\sum_{i} P\left(D_{i}\right)\left(2 P\left(B_{i} \mid D_{i}\right)-1\right)
$$

${ }^{1}$ The derivation is as follows: In Equation 1, we sum for any given trait the absolute differences between $P(B \mid D)$ and $\boldsymbol{P}_{\text {int }}(B \mid D)$ over (i) the congruent behavior and (ii) the incongruent behaviors. In symbols,

$$
\sum_{j}\left|P\left(B_{j} \mid D_{i}\right)-P_{\text {int }}\left(B_{j} \mid D_{i}\right)\right|=\left|P\left(B_{i} \mid D_{i}\right)-P_{\mathrm{int}}\left(B_{i} \mid D_{i}\right)\right|+\sum_{j \neq i}\left|P\left(B_{j} \mid D_{i}\right)-P_{\mathrm{int}}\left(B_{j} \mid D_{i}\right)\right| .
$$

Since $P_{\text {int }}\left(B_{i} \mid D_{i}\right)=1$,

$$
\left|\boldsymbol{P}\left(\boldsymbol{B}_{i} \mid D_{i}\right)-\boldsymbol{P}_{\mathrm{int}}\left(\boldsymbol{B}_{\boldsymbol{i}} \mid \boldsymbol{D}_{i}\right)\right|=1-\boldsymbol{P}\left(\boldsymbol{B}_{\mathbf{i}} \mid \boldsymbol{D}_{i}\right)
$$

and since $P_{\text {Int }}\left(B_{j} \mid D_{i}\right)=0$, for $j \neq i$

Hence

$$
\sum_{j \neq i}\left|P\left(B_{j} \mid D_{i}\right)-P_{\mathrm{int}}\left(B_{j} \mid D_{i}\right)\right|=\sum_{j \neq i} P\left(B_{j} \mid D_{i}\right)
$$

$$
\sum_{i} P\left(D_{i}\right)\left(1-\sum_{j}\left|P\left(B_{j} \mid D_{i}\right)-P_{\mathrm{int}}\left(B_{j} \mid D_{i}\right)\right|\right)=\sum_{i} P\left(D_{i}\right)\left(P\left(B_{i} \mid D_{i}\right)-\sum_{j \neq i} P\left(B_{j} \mid D_{i}\right)\right) .
$$


Thus, the amount of freedom for an actor who has a given disposition is represented by a simple linear function of the conditional probability that he will behave in a way congruent with his disposition, $\left(P\left(B_{i} \mid D_{i}\right)\right.$, or conditional probability of congruent behavior. This probability may be assessed for each disposition the actor may have. Since it may vary from one disposition to another, the amount of freedom attributed to the actor may vary too. For example, suppose an observer thinks that if an actor has $D_{1}$ the probability of his choosing the congruent behavior $B_{1}$ is .90 (i.e., $\left.P\left(B_{1} \mid D_{1}\right)=.90\right)$ and that if the actor has $D_{2}$ the probability of his choosing the congruent behavior $B_{2}$ is only .60 (i.e., $\mathrm{P}\left(B_{2} \mid D_{2}\right)=.60$ ). According to Equation 2, the actor would have more freedom if he had $D_{1}$ than if he had $D_{2}$. Therefore, as the prior probability of $D_{1}$ increases, the higher will be the expectancy that the actor's behavior will be congruent with the description and hence the higher will be the freedom attributed to him.

It should be noted, however, that recent work by Kahneman and Tversky (1973) indicates that inferences and predictions are often unaffected by the information contained in prior probabilities. People appear to rely almost exclusively on specific evidence, even when it is of little diagnostic value. According to Kahneman and Tversky, people predict events that best fit the evidence and disregard other considerations such as the base rates of the events. It is possible that freedom judgments are subject to a similar bias. Specifically, subjects may base their freedom judgments only on the likelihoods that the various dispositions actors may have will be expressed in behavior, ignoring the likelihoods of their actually having such dispositions. One purpose of the present study is to investigate this possibility.

In the experiments reported below, subjects considered actors who could have one of two dispositions, $D_{1}$ and $D_{2}$, and could choose between two behaviors, $B_{1}$ and $B_{2}$, which were overt expressions of these respective dispositions. Experiment 1 manipulated $P\left(B_{i} \mid D_{i}\right)$ and $P\left(D_{i}\right)$, with $P\left(B_{1} \mid D_{1}\right)>P\left(B_{2} \mid D_{2}\right)$. The disposition-behavior congruity model predicts that perceived freedom will be directly related to $P\left(B_{i} \mid D_{i}\right)$ and to $\mathrm{P}\left(D_{1}\right)$. Experiment 2 was designed to test a different procedure for manipulating $P\left(D_{i}\right)$ and to include a situation where the conditional probabilities of congruent behavior for the two dispositions were reversed, i.e., $\mathrm{P}\left(B_{1} \mid D_{1}\right)<P\left(B_{2} \mid D_{2}\right)$. In this case, the model predicts that perceived freedom will be inversely related to $P\left(D_{1}\right)$. Experiment 3 changed the freedom measure from a question (asked in the first two experiments) about the freedom that a group of actors have to a question about the freedom that an individual actor has. This allowed a more direct test of the model, which pertains to perception of an individual actor. Moreover, Experiment 3 manipulated orthogonally $P\left(B_{1} \mid D_{1}\right)$ and $P\left(B_{2} \mid D_{2}\right)$ so that their independent effects could be determined. 


\section{EXPERIMENT 1}

\section{Method}

Subjects. Ninety students (43 males and 47 females) from introductory courses in psychology at the University of Michigan participated in this experiment in groups ranging from 4 to 7 .

Design. A $3 \times 3$ factorial design was constructed involving three levels of $P\left(B_{i} \mid D_{i}\right)$ and three levels of $P\left(D_{i}\right)$. The former served as a within-subjects factor and the latter served as a between-subjects factor. Accordingly, 30 subjects were randomly assigned to each of the three levels of $P\left(D_{i}\right)$ and each subject responded to the three levels of $P\left(B_{i} \mid D_{i}\right)$.

Conditional probabilities of congruent behavior were selected at three levels: low, $P\left(B_{1} \mid D_{1}\right)=.68, P\left(B_{2} \mid D_{2}\right)=.53$; moderate, $P\left(B_{1} \mid D_{1}\right)=.815, \mathrm{P}\left(B_{2} \mid D_{2}\right)=.665$; and high, $P\left(B_{1} \mid D_{1}\right)=.95, P\left(B_{2} \mid D_{2}\right)=.80$. At each level $P\left(B_{1} \mid D_{1}\right)>P\left(B_{2} \mid D_{2}\right)$. Three distributions of prior probabilities of traits were employed: (a) $\mathrm{P}\left(D_{1}\right)=.2, P\left(D_{2}\right)=.8$; (b) $P\left(D_{1}\right)=P\left(D_{2}\right)$ $=.5$; and (c) $\mathrm{P}\left(D_{1}\right)=.8, P\left(D_{2}\right)=.2$. Since the conditional probability of congruent behavior associated with $D_{1}$ was greater than that associated with $D_{2}$, the model predicts that the higher $P\left(D_{1}\right)$, the greater the perceived freedom. The values predicted by the model are presented in Table 1.

Procedure. The experimenter informed subjects they would be given descriptions of three interview situations and would be asked to judge the amount of freedom interviewees had in these situations. The experimental task followed in a booklet titled "A Study on the Accuracy in Perceiving Others." Each subject read descriptions of three interview situations. These descriptions were generated by employing the following scenario:

In the Fall of 1971 there were a series of serious disturbances by students in three high schools in Los Angeles, California. These disturbances led to the cessation of studies in the schools. The issue was how to deal with students who cause and participate in serious disruptions of studies. The administrations of the schools proposed a new policy of expelling from school students who participate in disruption of studies. But this new policy aroused debate in the communities served by the schools. The school boards tended to disagree with the new policy proposed by the school administrations. Consequently, it was decided to establish in each school a committee to investigate the issue. Each investigating committee was composed of four members representing the two views on the issue. The school administration, which favored the new policy of expelling students who cause disruptions, was represented by the school superintendent and the assistant superintendent. The school board, which opposed expelling students who cause disruptions, was represented by the head of the school board and his assistant. As a first step, each committee decided to interview the teachers in its school. In these interviews, conducted separately with each teacher, the latter was asked to evaluate the new policy of expelling students who cause disruptions.

This scenario was designed to induce the perception that two types of social pressures may be operating in the situation. On one hand, the members of the school administration would want the actor (teacher) to argue in favor of the new policy. On the other hand, the members of the school board would prefer the actor to argue against this policy. Since teachers are dependent on both the school administration and the school board, each are potentially powerful sources of social pressure.

After describing these characteristics of the interview situations, the booklet instructed subjects to assume that teachers held either a positive attitude $\left(D_{1}\right)$ or a negative attitude $\left(D_{2}\right)$ toward the new policy and that during the interview a teacher argued either in favor of $\left(B_{1}\right)$ or against $\left(B_{2}\right)$ the new policy. The prior probabilities of dispositions were manipulated by informing subjects of the proportions of teachers in each school whose true attitude was 
positive or negative. $P\left(B_{i} \mid D_{i}\right)$ was manipulated by assigning one of the three levels mentioned in the design section to each of the three schoools being considered. This information was communicated by constructing a pair of bar diagrams for each school, one bar diagram representing teachers with a positive attitude and the other representing teachers with a negative attitude. Each diagram was divided into two portions, one of which represented the proportion of teachers who argued for the new policy, or $P\left(B_{1} \mid D_{i}\right)$, and the other represented the proportion of teachers who argued against it, or $P\left(B_{2} \mid D_{i}\right)$. The order in which the three schools were considered was counterbalanced across subjects.

After examining the diagrams, subjects were asked to judge how much freedom teachers had in the interview situations in each of the three schools. Subjects indicated their judgments on three rating scales corresponding to the three schools. These were 11-point scales with endpoints labeled "very little freedom" and "very much freedom."

\section{Results and Discussion}

Predicted values of perceived freedom $(P F)$ were derived for each of the nine experimental conditions on the basis of Equation 2. These values are given in part $\mathrm{A}$ of Table 1 . It is clear that for the values of the independent variables employed in the study the DBC model predicts that perceived freedom should be positive linear additive functions of both $P\left(D_{1}\right)$ and $P\left(B_{i} \mid D_{i}\right)$. Table 1, part B, presents mean ratings of perceived freedom for the nine experimental conditions.

The pattern of means in Table 1 unequivocally confirms the predicted effect of $P\left(B_{i} \mid D_{i}\right)$. Thus, the latter was associated with a robust main effect, $F(2,174)=44.22, p<.005$, with $99.98 \%$ of the variance due to this factor being accounted for by the linear component, $F(1,174)=88.26, p<.005$. However, disconfirming our hypothesis, the main effect of $P\left(D_{i}\right)$ was not significant, $F(2,87)<1$. As the model predicts, the two variables did not significantly interact, $F(4,174)=1.75$.

\section{TABLE 1}

Predicted and Obtained Values of Perceived Freedom for Nine Experimental Conditions Varying in Prior Probabilities of Dispositions and Conditional Probabilities of Congruent Behavior

\begin{tabular}{lccc}
\hline & \multicolumn{3}{c}{$\begin{array}{c}\text { Conditional probabilities of } \\
\text { congruent behaviors }\end{array}$} \\
\cline { 2 - 4 } $\begin{array}{c}\text { Values of per- } \\
\text { ceived freedom }\end{array}$ & Low & Moderate & High \\
\hline Predicted values & & & \\
low $P\left(D_{1}\right)$ & .12 & .39 & .66 \\
moderate $P\left(D_{1}\right)$ & .21 & .48 & .75 \\
high $P\left(D_{1}\right)$ & .30 & .57 & .84 \\
Obtained values & & & \\
low $P\left(D_{1}\right)$ & 4.99 & 6.21 & 6.95 \\
moderate $P\left(D_{1}\right)$ & 4.66 & 5.81 & 7.16 \\
high $P\left(D_{1}\right)$ & 4.27 & 6.47 & 7.99 \\
\hline
\end{tabular}




\section{EXPERIMENTS 2 AND 3}

The failure to obtain the predicted effect of $P\left(D_{i}\right)$ in Experiment 1 may indicate that priors are irrevalent to perceived freedom. However, before accepting this conclusion, another possibility should be considered, namely, that these probabilities were not sufficiently salient. Indeed, several procedural features of the experiment could have been responsible for subjects' insensitivity. First, since $P\left(D_{i}\right)$ was a between-subjects factor, subjects were exposed to just one of its values and could not experience variation on this dimension. Second, the bar diagrams for $D_{1}$ actors and $D_{2}$ actors had the same size; therefore, $\mathrm{P}\left(D_{1}\right)$ and $P\left(D_{2}\right)$ were not represented visually.

Experiment 2 was designed to eliminate these potential sources of insensitivity to $P\left(D_{i}\right)$. A third experiment was designed to answer two additional questions that had not been studied in Experiment 1. The first question was whether $P\left(B_{1} \mid D_{1}\right)$ and $P\left(B_{2} \mid D_{2}\right)$ have independent effects on perceived freedom, as implied by Equation 2 . To investigate this matter, $P\left(B_{1} \mid D_{1}\right)$ and $P\left(B_{2} \mid D_{2}\right)$ were orthogonally manipulated. The second question concerned the freedom measure. In Experiment 1, freedom was attributed to a group of teachers, the assumption being that similar attributions would also have been made to a single member of the group if no further individuating information were given. However, to avoid the necessity of making this assumption, subjects in Experiment 3 made freedom attributions to an individual teacher.

\section{Method}

Experiment 2. Subjects were 93 students ( 40 males and 53 females) from introductory courses in psychology at the University of Michigan. One group of 48 subjects responded to four out of the nine experimental conditions of Experiment 1. Specifically, the two extreme le vels of $P\left(D_{1}\right)$ (low and high) were crossed with the two extreme levels of $P\left(B_{i} \mid D_{i}\right)$ (low and high) in a $2 \times 2$ factorial design. For another group of 45 subjects, the value of $P\left(B_{1} \mid D_{1}\right)$ and $P\left(B_{2} \mid D_{2}\right)$ under the four conditions were reversed, so that $P\left(B_{2} \mid D_{2}\right)>P\left(B_{1} \mid D_{1}\right)$.

The procedure was identical to that employed in Experiment 1, with the following exceptions: First, subjects were given descriptions of interview situations in four schools. Second, the heights of the bar diagrams that displayed the conditional probabilities for teachers holding a positive attitude and for teachers holding a negative attitude were proportional to the prior probabilities of the two types of teachers. For example, in the conditions where $\mathrm{P}\left(D_{1}\right)=.2$ and $P\left(D_{2}\right)=.8$, the height of the bar diagram for teachers holding a negative attitude was four times higher than that for teachers holding a positive attitude.

Experiment 3. A total of 45 students ( 24 males and 21 females) from an introductory course in psychology at the Hebrew University of Jerusalem participated individually in this experiment.

The values of $P\left(B_{1} \mid D_{1}\right)$ and $P\left(B_{2} \mid D_{2}\right)$ were manipulated independently. Specifically, two levels of $P\left(B_{1} \mid D_{1}\right), .55$ and .95 , were crossed with two levels of $P\left(B_{2} \mid D_{2}\right), .60$ and .90 , in a $2 \times 2$ factorial design. Each subject responded to the four resulting situations (schools), in which $\mathrm{P}\left(D_{1}\right)$ was held constant at $P\left(D_{1}\right)=P\left(D_{2}\right)=.50$. 
The information about the schools was presented in the same way as in the previous experiments, except for slight changes designed to adapt the description to the situation in Israeli schools. Also, in this experiment the perceived freedom question asked: "Imagine one of the teachers from this school. How much freedom did he have in the interview situation?"

\section{Results and Discussion}

Experiment 2. The pattern of means obtained in Experiment 1 was also obtained here. Consider first the group that was told that $\mathrm{P}\left(B_{1} \mid D_{1}\right)$ $>P\left(B_{2} \mid D_{2}\right)$. The means for low $P\left(D_{1}\right)$ and high $\mathrm{P}\left(D_{1}\right)$ were 4.65 and 4.64 , respectively, in the low $P\left(B_{i} \mid D_{i}\right)$ condition, and were 7.63 and 7.56, respectively, in the high $P\left(B_{i} \mid D_{i}\right)$ condition. Thus, $P\left(B_{i} \mid D_{i}\right)$ was the only significant determinant of perceived freedom, $F(1,47)=40.66, p<.005$. The expected positive relation between perceived freedom and $P\left(D_{1}\right)$ was not obtained.

For the case where $P\left(B_{2} \mid D_{2}\right)>P\left(B_{1} \mid D_{1}\right)$, the DBC model predicts a negative relation between perceived freedom and $P\left(D_{1}\right)$. The results indicated, however, the same insensitivity to prior probabilities. In the low $\mathrm{P}\left(B_{i} \mid D_{i}\right)$ condition, the means for low $P\left(D_{1}\right)$ and high $P\left(D_{1}\right)$ were identical (4.32), and in the high $P\left(B_{i} \mid D_{i}\right)$ condition these means were 7.23 and 7.79, respectively. Again, the only significant effect was that of $P\left(B_{i} \mid D_{i}\right)$, $F(1,44)=52.07, p<.005$.

With the procedure employed in this experiment, it seems unlikely that subjects were not aware of variations in prior probabilities. ${ }^{2}$ It appears that subjects "knowingly" ignored these probabilities in judging freedom.

Experiment 3. As expected, perceived freedom was higher when $P\left(B_{1} \mid D_{1}\right)$ was high $(M=7.52)$ than when it was low $(M=5.49)$, $F(1,44)=51.72, p<.001$, and was higher when $P\left(B_{2} \mid D_{2}\right)$ was high $(M=7.39)$ than when it was low $(M=5.62), F(1,44)=66.08, p<.001$. Furthermore, as predicted the interaction of these variables was not significant, $F(1,44)=1.50$. The results of this preliminary experiment corrobroated, then, the assumption of the DBC model that both conditional probabilities of congruent behaviors are taken into account and that they are combined additively in attribution of freedom to an individual actor.

\footnotetext{
${ }^{2}$ In fact, additional data on trait inference which we obtained in conjunction with Experiments 1 and 2 indicate that subjects were indeed aware of variation in $P\left(D_{i}\right)$. After being informed about the behavior of a particular actor, subjects estimated the posterior probabilities of the actor possessing $D_{1}$ or $D_{2}$. Whereas in Experiment 1 these estimates were not consistently affected by prior probabilities, significant effects were obtained in Experiment 2-the higher the prior probability of a disposition, the higher its posterior probability. However, even in Experiment 2 the weight subjects gave to prior probabilities was too small, and the weight they gave to conditional probabilities was too large, as compared to an optimal Bayesian model of probabilistic inference. Consequently, for example, the posterior probability of a disposition favored by prior probabilities was not high enough after observing a behavior congruent with the disposition; the posterior probability of this disposition was too low when an incongruent behavior was reported. (See Trope, Note 1, for more details.)
} 


\section{CONCLUSION}

The data suggest that the DBC model, as expressed in Equations 1 and 2 should be modified. Since there is no evidence that subjects weigh the conditional probabilities of congruent behavior by the prior probabilities of the respective dispositions, we can write these equations as simple rather than weighted averages or sums. These revisions retain the basic notion underlying the $\mathrm{DBC}$ model, that is, freedom is attributed to the extent that actors' behaviors are expected to be guided by their dispositions.

The conclusion that priors do not affect perceived freedom should be qualified. More specifically, in this study prior information was given in the form of relative frequencies or base rates of the dispositions in some population. It is possible that specific prior information about individual actors (e.g., personality sketches) would have an effect. This possibility is suggested by Kahneman and Tversky's (1973) and Nisbett and Borgida's (1975) research which shows that people tend to ignore base rate frequencies in various judgmental tasks. Nisbett and Borgida (1975) argue that base rates are typically abstract and pallid whereas evidence about particular cases is vivid and concrete. Tversky and Kahneman (Note 2) posit that base rate information is disregarded because it is not readily interpreted as causal propensities that apply to the individual case. Moreover, Tversky and Kahneman demonstrated that subjects do integrate base rates into judgments when base rates are interpreted as reflecting some causal process on the level of individual cases. This finding may explain why our subjects made use of $P\left(B_{i} \mid D_{i}\right)$ despite the fact that this information was presented by means of relative frequencies. Specifically, subjects were perhaps able to interpret differences in these relative frequencies as differences in the magnitude of situational forces that block expression of the dispositions considered. Moreover, they could perhaps easily imagine how these forces concretely affect each individual.

Attribution theory assumes that confidence in inference of dispositions from behavior is positively related to perceived freedom (Kelley, 1967; Nisbett and Valins, 1972). This relationship is clearly implied by the DBC model: When actors are expected to behave in line with their dispositions, their hehaviors are perfect indicators of their dispositions. In terms of probabilistic inference, with high $P\left(B_{i} \mid D_{i}\right)$ the behaviors are differentially associated with dispositions, so that after a given behavior is observed the probability of the corresponding disposition should also be high (see Trope, 1974; Trope \& Burnstein, 1975). Extrinsic considerations introduce equivocality in the relationship between behaviors and corresponding dispositions and therefore reduce perceived freedom as well as confidence in attributing behavior to an underlying disposition.

Finally, it is worth considering our results in relation to Steiner's (1970) conceptions of decision freedom. This can be readily done since the latter 
has been formulated in terms of behavior probabilities, i.e., the more nearly equiprobable the behavior alternatives, the higher the decision freedom (Ajzen, 1971). In our experiments, the probability of each behavior alternative, $\mathrm{P}\left(\boldsymbol{B}_{j}\right)$, can be estimated for each condition as follows: $P\left(B_{j}\right)=\sum_{i}\left(\mathrm{D}_{i}\right) P\left(B_{j} \mid D_{i}\right)$. Examination of these probabilities in Experiment 1 , for instance, would show that they become more nearly equal as $P\left(B_{i} \mid D_{i}\right)$ and $P\left(D_{1}\right)$ decrease. None of these trends was manifested in the data of Experiment 1. Similarly, the data from Experiments 2 and 3 showed no trace of positive relationship between perceived freedom and nearness to equality of the behavior probability. We may conclude then that our results cannot be interpreted in terms of perceived decision freedom.

\section{REFERENCES}

Ajzen, I. Attribution of a disposition to an actor: Effect of perceived decision freedom and behavioral utilities. Journal of Personality and Social Psychology, 1971, 18, 149-156.

Brehm, J. W. A theory of psychological reactance. New York: Academic Press, 1966.

Brehm, J. W., \& Cohen, A. R. Explorations in cognitive dissonance. New York: Wiley, 1962.

Harvey, J. H., \& Harris, B. Determinants of perceived choice and the relationship between perceived choice and expectancies about feelings of internal control over own behavior. Journal of Personality and Social Psychology, 1975, 31, 101-106.

Harvey, J. H., \& Johnston, S. Determinants of the perception of choice. Journal of Experimental Social Psychology, 1973, 9, 164-179.

Jellison, J. M., \& Harvey, J. H. Determinants of perceived choice and the relationship between perceived choice and perceived competence. Journal of Personality and Social Psychology, 1973, 28, 376-382.

Jones, E. E., \& Davis, K. E. Frum acts to dispositions: The attribution process in person perception. In L. Berkowitz (Ed.), Advances in experimental social psychology. New York: Academic Press, 1965. Vol. 2.

Kahneman, D. \& Tversky. A. On the psychology of prediction. Psycholngical Review, 1973, 80, 237-251.

Kelley, H. H. Attribution theory in social psychology. In D. Levine (Ed.), Nebraska symposium on motivation. Lincoln, Nebraska: University of Nebraska Press, 1967.

Kelley, H. H. Attribution in soical interaction. New York: General Learning Press, 1971.

Kruglanski, A. W. The endogenous-exogenous partition in attribution theory.P sychological Review, 1975, 82, 387-406.

Kruglanski, $\Lambda$. W., \& Cohen, M. Attributed frecdom and pcrsonal causality. Journal of Personality and Social Psychology, 1973, 31, 245-250.

Kruglanski, A. W., \& Cohen, M. Attributing freedom in the decision context: Effects of the choice alternatives, degrees of commitment and pre-decision uncertainty. Journal of Personality and Social Psychology, 1974, 30, 178-187.

Nisbett, R. E., \& Borgida, E. Attribution and the psychology of prediction. Journal of Personality and Social Psychology, 1975, 32, 932-943.

Nisbett, R. E., \& Valins, S.Perceiving the causes of one's own behavior. New York: General Learning Press, 1971.

Steiner, I. D. Perceived freedom. In L. Berkowitz (Ed.), Advances in experimental social psychology. New York: Academic Press, 1970. Vol. 5.

Steiner, I. D., Rotermund, M., \& Talaber, R. Attribution of choice to a decision maker. Journal of Personality and Social Psychology, 1974, 30, 553-562.

Trope, Y. Inferential processes in the forced compliance situation: A Bayesian analysis. Journal of Experimental Social Psychology, 1974, 10, 1-16. 
Trope, Y., \& Burnstein, E. Processing the information contained in another's behavior. Journal of Experimental Social Psychology, 1975, 11, 439-458.

\section{REFERENCE NOTES}

Trope, Y. A probabilistic information processing approach to attribution processes. Unpublished doctoral dissertation, University of Michigan, 1974.

Tversky, A., \& Kahneman, D. Causal thinking in judgment under uncertainty. Unpublished manuscript, Hebrew University of Jerusalem, 1976. 